\title{
On the performance of cooperative cognitive networks with selection combining and proactive relay selection
}

\section{- Ho Van Khuong}

- Vo Que Son

- Luu Thanh Tra Ho Chi Minh city University of Technology, VNU-HCM, Vietnam

\section{- Pham Hong Lien}

University of Technical Education, Ho Chi Minh city, Vietnam

(Manuscript Received on July 15, 2015, Manuscript Revised August 30, 2015)

\section{ABSTRACT:}

This paper proposes an outage analysis framework for cooperative cognitive networks with proactive relay selection and selection combining (SC) under licensed outage constraint, maximum transmit power constraint, independent non-identical (i.n.i) fading distributions, erroneous channel information, and licensed users' interference. Towards this end, we firstly suggest power allocation for unlicensed transmitters to satisfy power constraints and account for erroneous channel information and licensed

users' interference. Then, we propose an exact closed-form outage probability formula for the unlicensed network to promptly evaluate system performance and provide useful insights into performance limits. Multiple results show performance trade-off between the unlicensed network and the licensed network, error floor in the unlicensed network, considerable system performance degradation owing to erroneous channel information and licensed users' interference, and significant performance enhancement due to the increase in the number of relays.

Keywords: Proactive relay selection, erroneous channel information, cognitive radio.

\section{INTRODUCTION}

Currently, many emerging wireless services such as high definition video streaming, video calling, file transferring and high-speed internet access demand more and more radio spectrum while the conventional allocation of frequency bands by means of fixed licensed users (LUs) is not efficient, causing spectrum shortage. This shortage conflicts with a severe spectrum underutilization as reported in an extensive survey on frequency spectrum utilization carried out by the
Federal Communications Commission [1]. A cognitive radio (CR) technology has been recently proposed to resolve this contrast [2]. The philosophy behind this technology is the coexistence of unlicensed users (UUs) and LUs on the frequency band inherently allotted to the LUs subject to an acceptable quality of service (QoS) at LUs. However, the interference from UUs on LUs becomes a great challenge to the CR technology. To control this interference, UUs 
wisely limit their transmit power to ensure that the induced interference at LUs remains below a controllable level, ultimately reducing their communication range. To extend the communication range for UUs, relaying communications technique should be integrated into UUs [3]. In relaying communications, relay selection criteria plays a very important role in improving system performance in terms of spectral efficiency, power consumption, and transmission reliability.

To optimize system design such as optimum power allocation, channel information is required to be available. Nevertheless, this information is inevitably erroneous, inducing the study on the impact of channel information error on the outage performance of relay selection criterions in cooperative cognitive networks to be essential. The effect of channel information error on the proactive, reactive, partial relay selection criteria was investigated in [5], [6], and [4], [7], [8], respectively. However, [4]-[8] assumed no licensed users' interference, independent and partially-identical fading distributions, and no licensed outage constraint.

Motivated by the above, this paper proposes an outage analysis framework for the proactive relay selection in cooperative cognitive networks under practical operation conditions such as maximum transmit power constraint, channel information error, i.n.i fading distributions, licensed outage constraint, and licensed users' interference to evaluate system performance quickly and to expose performance limits.

The structure of this paper is as follows. The next section presents the system model under investigation. Power allocation for UUs is discussed in Section 3. An exact closed-form outage probability formula for the unlicensed network is elaborately derived in Section 4. Results for validating the proposed formulas and demonstrating the outage performance of the proactive relay selection in cooperative cognitive networks are presented in Section 5. Finally, the paper is closed with useful remarks in Section 6.

\section{SYSTEM MODEL}

Figure 1 shows a cooperative cognitive network with the proactive relay selection where the best unlicensed relay $\mathrm{UR}_{b}$ in the group of $J$ unlicensed relays, $\mathrm{R}=\left\{\mathrm{UR}_{1}, \mathrm{UR}_{2}, \ldots, \mathrm{UR}_{J}\right\}$ assists communication between the unlicensed source US and the unlicensed destination UD . Independent, frequency-flat, and Rayleighdistributed fading channels are considered and hence, the channel coefficient, $h_{k l p}$, between the transmitter $k$ and the receiver $l$ in the phase $p$ can be modelled as a circular symmetric complex Gaussian random variable with zero mean and $\lambda_{k l p}$ -variance, i.e. $h_{k l p} \sim \mathrm{CN}\left(0, \lambda_{k l p}\right)$, as illustrated in Table 1.

To support performance analysis in presence of channel estimation error (CEE), we applied the well-known CEE model (e.g., [9]) where the relation between the real channel coefficient, $h_{k l p}$, and its estimated one, $\hat{h}_{k l p}$, is given by

$$
\hat{h}_{k l p}=\rho h_{k l p}+\sqrt{1-\rho^{2}} \varepsilon_{k l p}
$$

where $\varepsilon_{k l p}$ is the CEE and $\rho$ is the correlation coefficient, $\quad 0 \leq \rho \leq 1$, characterizing the average quality of channel estimation. Similarly to [9], all random variables $\left\{\hat{h}_{k p}, h_{k l p}, \varepsilon_{k l p}\right\}$ are modelled as $\mathrm{CN}\left(0, \lambda_{k p}\right)$.

Figure 1 shows that the proactive relay selection in cooperative cognitive networks takes place in two phases. In the phase 1 , u s sends the signal $x_{S}$ with transmit power $P_{S}$ (i.e., $P_{S}=\mathrm{E}_{x_{S}}\left\{\left|x_{S}\right|^{2}\right\}$ where $\mathrm{E}_{X}\{x\}$ stands for the expectation operator over random variable $X$ ) while L T is simultaneously sending the signal $x_{L 1}$ with transmit power $P_{L}$. The signals from US 
and L T cause the mutual interference between the licensed network and the unlicensed network. Therefore, the received signals at the licensed receiver $L R$ and the unlicensed receivers (i.e., $\mathrm{UR}_{j}$, and UD ), respectively, can be given by

$$
\begin{aligned}
y_{L L 1} & =h_{L L 1} x_{L 1}+h_{S L 1} x_{S}+n_{L 1} \\
y_{S l 1} & =h_{S l 1} x_{S}+h_{L 1} x_{L 1}+n_{l 1}, \quad l \in\{D, \mathrm{~J}\}
\end{aligned}
$$
where $n_{l p} \sim \mathrm{CN}\left(0, N_{0}\right)$ is the additive

white Gaussian noise (AWGN) at the corresponding receivers.

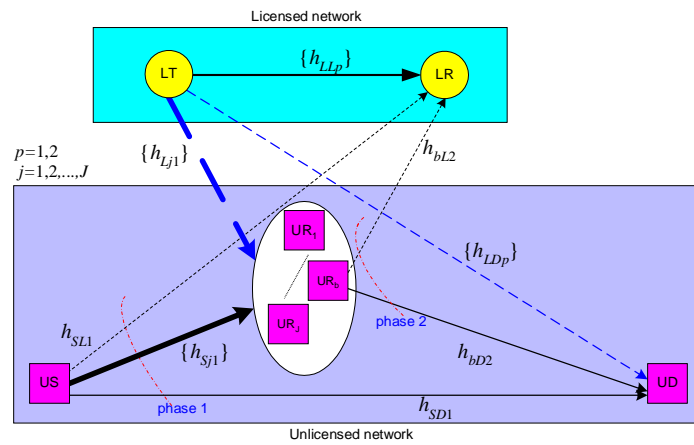

Figure 1. System model

Table 1. Notations for channel coefficients: $\mathrm{J}=\{1, \ldots J\}$.

\begin{tabular}{|c|l|}
\hline Notation & \multicolumn{1}{|c|}{$\begin{array}{c}\text { Channel coefficient } \\
\text { between }\end{array}$} \\
\hline$h_{L L p} \sim \mathrm{CN}\left(0, \lambda_{L L p}\right)$ & $\begin{array}{l}\mathrm{LT} \text { and L R in the } \\
\text { phase } p\end{array}$ \\
\hline$h_{L j 1} \sim \mathrm{CN}\left(0, \lambda_{L j 1}\right)$ & $\begin{array}{l}\mathrm{LT} \quad \text { and } \quad \mathrm{UR}_{j}, \\
j \in \mathrm{J}\end{array}$ \\
\hline$h_{L D p} \sim \mathrm{CN}\left(0, \lambda_{L D p}\right)$ & $\begin{array}{l}\mathrm{LT} \text { and } \mathrm{UD} \quad \text { in the } \\
\text { phase } p\end{array}$ \\
\hline$h_{S L 1} \sim \mathrm{CN}\left(0, \lambda_{\mathrm{L} 1}\right)$ & $\mathrm{US}$ and L R \\
\hline$h_{S j 1} \sim \mathrm{CN}\left(0, \lambda_{S j 1}\right)$ & $\begin{array}{l}\mathrm{US} \quad \text { and } \\
j \in \mathrm{J}\end{array}$ \\
\hline$h_{j D p} \sim \mathrm{CN}\left(0, \lambda_{j D p}\right)$ & $\begin{array}{l}\mathrm{UR} \\
j \in \mathrm{J}\end{array}$ \\
\hline$h_{S D 1} \sim \mathrm{CN}\left(0, \lambda_{S D 1}\right)$ & $\mathrm{US}$ and UD \\
\hline
\end{tabular}

\begin{tabular}{|c|l|}
\hline Notation & \multicolumn{2}{|c|}{$\begin{array}{c}\text { Channel coefficient } \\
\text { between }\end{array}$} \\
\hline$h_{j L 2} \sim \mathrm{ON}\left(0, \lambda_{j L 2}\right)$ & $\begin{array}{l}\mathrm{UR}_{j} \quad \text { and } \quad \mathrm{L} \mathrm{R}, \\
j \in \mathrm{J}\end{array}$ \\
\hline
\end{tabular}

Using (1) to rewrite (2) and (3) as

$$
\begin{aligned}
y_{L L 1}= & \frac{\hat{h}_{L L 1}}{\rho} x_{L 1}-\frac{\sqrt{1-\rho^{2}}}{\rho} \varepsilon_{L L 1} x_{L 1}+h_{S L 1} x_{S}+n_{L 1}(4) \\
y_{S l 1}= & \frac{\hat{h}_{S l 1}}{\rho} x_{S}-\frac{\sqrt{1-\rho^{2}}}{\rho} \varepsilon_{S l 1} x_{S} \\
& +h_{L l 1} x_{L 1}+n_{l 1}, \quad l \in\{D, \mathrm{~J}\}
\end{aligned}
$$

which result in the signal-to-interference plus noise ratio (SINR) at the licensed receiver and the unlicensed receivers in the phase 1 as

$$
\begin{gathered}
\Psi_{L L 1}=\frac{\left|\hat{h}_{L L 1}\right|^{2} P_{L}}{\left(1-\rho^{2}\right) \lambda_{L L 1} P_{L}+\left|h_{S L 1}\right|^{2} \rho^{2} P_{S}+\rho^{2} N_{0}} \\
\Psi_{S l 1}=\frac{\left|\hat{h}_{S l 1}\right|^{2} P_{S}}{\left(1-\rho^{2}\right) \lambda_{S l 1} P_{S}+\rho^{2}\left|h_{L l 1}\right|^{2} P_{L}+\rho^{2} N_{0}} \\
, l \in\{D, \mathrm{~J}\}
\end{gathered}
$$

This paper analyzes the outage performance of the proactive relay selection in cooperative cognitive networks. According to the proactive relay selection criterion, the selected relay $\mathrm{UR}_{b}$ is the one that obtains the largest end-to-end SINR, i.e.

$$
b=\arg \max _{j \in \mathrm{J}} \min \left(\Psi_{S j 1}, \Psi_{j D 2}\right)
$$

where $\Psi_{j D 2}$ is the SINR of the signal received at $\mathrm{UD}$ from $\mathrm{UR}_{j}$ in the phase 2. This signal can be represented in the same form as (5), i.e.

$$
\begin{aligned}
y_{j D 2}= & \frac{\hat{h}_{j D 2}}{\rho} x_{j}-\frac{\sqrt{1-\rho^{2}}}{\rho} \varepsilon_{j D 2} x_{j} \\
& +h_{L D 2} x_{L 2}+n_{D 2}
\end{aligned}
$$

where $j \in \mathrm{J}, x_{L 2}$ is the signal transmitted by L T with the power $P_{L}$, and $x_{j}$ is the signal transmitted 
by $\mathrm{UR}_{j}$ with the power $P_{j}$. As such, $\Psi_{j D 2}$ can be computed in the same way as (7), i.e.

$$
\Psi_{j D 2}=\frac{\left|\hat{h}_{j D 2}\right|^{2} P_{j}}{\left(1-\rho^{2}\right) \lambda_{j D 2} P_{j}+\rho^{2}\left|h_{L D 2}\right|^{2} P_{L}+\rho^{2} N_{0}}
$$

In the phase 2, LR also receives the desired signal from $\mathrm{LT}$ and the inference signal from $\mathrm{UR}_{b}$. Therefore, the SINR at LR in the phase 2 can be expressed in the same form as (6), i.e.

$$
\Psi_{L L 2}=\frac{\left|\hat{h}_{L L 2}\right|^{2} P_{L}}{\left(1-\rho^{2}\right) \lambda_{L L 2} P_{L}+\left|h_{b L 2}\right|^{2} \rho^{2} P_{b}+\rho^{2} N_{0}}
$$

To recover the source information with low implementation complexity, both signals received from US and $\mathrm{UR}_{b}$ can be selection-combined at UD, which results in the total SINR at UD as $\Psi_{t o t}=\max \left(\Psi_{S D 1}, \max _{j \in \mathrm{J}} \min \left(\Psi_{S j 1}, \Psi_{j D 2}\right)\right)$

\section{POWER ALLOCATION FOR UNLICENSED USERS}

To guarantee QoS for LUs [10], the power of unlicensed transmitters must be properly allocated to meet the licensed outage constraint. To this effect, the transmit powers of US and $\mathrm{UR}_{b}$ must be limited to satisfy the following two licensed outage constraints, correspondingly:

$$
\begin{aligned}
& \operatorname{Pr}\left\{\log _{2}\left(1+\Psi_{L L 1}\right)<\eta_{L}\right\}=F_{\Psi_{L 1}}\left(\tau_{L}\right) \leq \mu \\
& \operatorname{Pr}\left\{\log _{2}\left(1+\Psi_{L L 2}\right)<\eta_{L}\right\}=F_{\Psi_{L 2}}\left(\tau_{L}\right) \leq \mu
\end{aligned}
$$

where $\operatorname{Pr}\{X\}$ stands for the probability of the event $X, \tau_{L}=2^{\eta_{L}}-1$ with $\eta_{L}$ being the required transmission rate in the licensed network, $F_{X}(x)$ signifies the cumulative distribution function (cdf) of $X$, and $\mu$ is the required outage probability of LUs.
Moreover, unlicensed transmitters (i.e., US and $\mathrm{UR}_{b}$ are constrained by their designed maximum transmit powers (i.e., $P_{S m}$ and $P_{b m}$ ). Therefore, the transmit powers of US and $\mathrm{UR}_{b}$ are also upper-bounded by $P_{S m}$ and $P_{b m}$, respectively, i.e.

$$
\begin{aligned}
& P_{S} \leq P_{S m} \\
& P_{b} \leq P_{b m}
\end{aligned}
$$

Theorem: For the maximum transmission range, the transmit power of a unlicensed user that satisfies both the licensed outage constraint and the maximum transmit power constraint is given by

$$
\left.P_{k}=\min \{\underbrace{\frac{P_{L} \lambda_{L L p}}{\tau_{L} \rho^{2} \lambda_{k L p}}\left[\frac{(1-\mu)^{-1}}{e^{\tau_{L}\left(1-\rho^{2}+\frac{\rho^{2} N_{0}}{P_{L} \lambda_{L L p}}\right)}}-1\right.}_{\mathrm{L}}]^{+}, P_{k m}\right\}
$$

where $[x]^{+}$denotes $\max (x, 0)$ and the phase 1 corresponds to $(k, p)=(S, 1)$ while the phase 2 corresponds to $(k, p)=(b, 2)$.

Proof: The proof for $(k, p)=(S, 1)$ is presented, which is straightforwardly extended to $(\mathrm{k}, \mathrm{p})=(\mathrm{b}, 2)$ for completing the whole proof of Theorem.

Let $\quad X=\left|\hat{h}_{L L 1}\right|^{2} P_{L} \quad$ and $Y=\left(1-\rho^{2}\right) \lambda_{L L 1} P_{L}+\left|h_{S L 1}\right|^{2} \rho^{2} P_{S}+\rho^{2} N_{0}$.

Since $\hat{h}_{L 1} \sim \mathrm{CN}\left(0, \lambda_{L L 1}\right)$ and $h_{\mathrm{SL1}} \sim \mathrm{CN}\left(0, \lambda_{\mathrm{SL1}}\right)$, the probability density function (pdf) of $X$ and the pdf of $Y$, correspondingly are given by

$$
f_{X}(x)=\frac{1}{P_{L} \lambda_{L L 1}} e^{-\frac{x}{P_{L} \lambda_{L L 1}}}, x \geq 0
$$




$$
f_{Y}(x)=\frac{1}{\rho^{2} P_{S} \lambda_{S L 1}} e^{-\frac{x-u}{\rho^{2} P_{S} \lambda_{S L 1}}}, x \geq u
$$

where $u=\left(1-\rho^{2}\right) \lambda_{L L 1} P_{L}+\rho^{2} N_{0}$.

Given $\Psi_{L L 1}=X / Y$ in (6), it immediately follows that

$$
F_{\Psi_{L 1}}\left(\tau_{L}\right)=\int_{u}^{\infty}\left[\int_{0}^{\tau_{L} y} f_{X}(x) d x\right] f_{Y}(y) d y
$$

Substituting (18) and (19) into (20) and performing simplifications, one obtains the closed-form expression of $F_{\Psi_{L 1}}\left(\tau_{L}\right)$ as

$$
F_{\Psi_{L L 1}}\left(\tau_{L}\right)=1-\frac{P_{L} \lambda_{L L 1} e^{-\tau_{L} \varphi_{L L 1}}}{P_{L} \lambda_{L L 1}+\tau_{L} \rho^{2} P_{S} \lambda_{S L 1}}
$$

where $\varphi_{L L 1}=1-\rho^{2}+\rho^{2} N_{0} / P_{L} \lambda_{L L 1}$.

Using (21), we deduce $P_{S}$ that meets (13) as

$$
P_{S} \leq \frac{P_{L} \lambda_{L L 1}}{\tau_{L} \rho^{2} \lambda_{S L 1}}\left(\frac{e^{-\tau_{L} \varphi_{L L 1}}}{1-\mu}-1\right)
$$

When $e^{-\tau_{L} \varphi_{L 1}}+\mu<1$, the right-hand side of (22) becomes negative. As such, the constraint in (13) is equivalent to

$$
P_{S} \leq \frac{P_{L} \lambda_{L L 1}}{\tau_{L} \rho^{2} \lambda_{S L 1}}\left[\frac{e^{-\tau_{L} \varphi_{L L 1}}}{1-\mu}-1\right]^{+}
$$

Finally, combining (23) with (15) results in

$$
P_{S} \leq \min \left(\frac{P_{L} \lambda_{L L 1}}{\tau_{L} \rho^{2} \lambda_{S L 1}}\left[\frac{e^{-\tau_{L} \varphi_{L L 1}}}{1-\mu}-1\right]^{+}, P_{S m}\right)
$$

To maximize the communication range, the equality in (24) must hold, and hence, $P_{S}$ is reduced to (17) for $(k, p)=(S, 1)$, completing the proof.

\footnotetext{
${ }^{1}$ Due to the two-phase nature of the proactive relay selection, $\tau_{S}$ is related to the required transmission rate, $\eta_{S}$, in the unlicensed network as $\tau_{S}=2^{2 \eta_{S}}-1$.
}

\section{OUTAGE ANALYSIS}

This section presents a formula of outage probability, which is defined as the probability that the total SINR is below a predefined ${ }^{1}$ threshold $\tau_{S}$, i.e.

$$
\begin{aligned}
& O P=\operatorname{Pr}\left\{\Psi_{t o t} \leq \tau_{s}\right\} \\
& =\operatorname{Pr}\left\{\max \left(\Psi_{S D 1}, \max _{j \in \mathrm{J}} \min \left(\Psi_{S j 1}, \Psi_{j D 2}\right)\right)\right. \\
& \left.\leq \tau_{s}\right\} \\
& =\underbrace{\operatorname{Pr}\left\{\Psi_{S D 1} \leq \tau_{S}\right\}}_{\mathrm{M}_{1}} \times \\
& \underbrace{\operatorname{Pr}\left\{\max _{j \in \mathrm{J}} \min \left(\Psi_{S j 1}, \Psi_{j D 2}\right) \leq \tau_{s}\right\}}_{\mathrm{M}_{2}}
\end{aligned}
$$

Before presenting closed-form expressions of $M_{1}$ and $M_{2}$ for completing the analytic evaluation of (25), we introduce the cdf of $\Psi_{s / 1}$ where $l=\{D, \mathrm{~J}\}$. Similarly to (21), one obtains the cdf of $\Psi_{S 1}$ as

$$
F_{\Psi_{S l 1}}(x)=1-\frac{G_{S l 1}}{x+G_{S l 1}} e^{-\varphi_{S l 1} x}, x \geq 0
$$

where $\quad G_{S l 1}=P_{S} \lambda_{S l 1} / \rho^{2} P_{L} \lambda_{L l 1} \quad$ and $\varphi_{S l 1}=1-\rho^{2}+\rho^{2} N_{0} / P_{S} \lambda_{S l 1}$.

It is seen that $M_{1}$ is the cdf of $\Psi_{S D 1}$ evaluated at $\tau_{S}$, i.e.

$$
\mathrm{M}_{1}=F_{\Psi_{S D 1}}\left(\tau_{S}\right)
$$

We rewrite $\mathrm{M}_{2}$ in (25) as

$$
\begin{aligned}
\mathrm{M}_{2} & =\mathrm{E}_{\left|h_{L D 2}\right|^{2}}\left\{\operatorname { P r } \left\{\max _{j \in \mathrm{J}} \min \left(\Psi_{S j 1}, \Psi_{j D 2}\right)\right.\right. \\
& \left.\left.\leq\left.\tau_{S}|| h_{L D 2}\right|^{2}\right\}\right\}
\end{aligned}
$$




$$
\begin{aligned}
& =\mathrm{E}_{\left|h_{L D 2}\right|^{2}}\left\{\prod _ { j \in J } \operatorname { P r } \left\{\min \left(\Psi_{S j 1}, \Psi_{j D 2}\right)\right.\right. \\
& \left.\left.\leq\left.\tau_{S}|| h_{L D 2}\right|^{2}\right\}\right\} \\
& =\mathrm{E}_{\left|h_{L D 2}\right|^{2}}\left\{\prod_{j \in J}\left(1-\mathrm{Q}_{j} \mathrm{~T}_{j}\right)\right\}
\end{aligned}
$$

where

$\mathrm{Q}_{j}=\operatorname{Pr}\left\{\Psi_{s_{j 1}} \geq \tau_{s}\right\}=1-F_{\Psi_{s, 1}}\left(\tau_{s}\right)(29)$

$\mathrm{T}_{j}=\operatorname{Pr}\left\{\Psi_{j D 2} \geq\left.\tau_{S}|| h_{L D 2}\right|^{2}\right\}$

(30)

Using (10) to compute $\mathrm{T}_{j}$ in (30) as

$\mathrm{T}_{j}=e^{-\tau_{S}\left(\varphi_{j D 2}+\frac{\rho^{2} P_{L}}{\lambda_{j D 2} P_{j}}\left|h_{L D 2}\right|^{2}\right)}$

where $P_{j}$ has the same form as (17) with changing $k$ to $j$ and

$\varphi_{j D 2}=1-\rho^{2}+\frac{\rho^{2} N_{0}}{\lambda_{j D 2} P_{j}}$

Using the fact that

$\prod_{j \in J}\left(1-u_{j}\right)=1+(-1)^{J} \prod_{j \in J} u_{j}$

$+\sum_{i=1}^{J-1}(-1)^{i} \sum_{w_{1}=1}^{J-i+1} \sum_{w_{2}=w_{1}+1}^{J-i+2} \cdots \sum_{w_{i}=w_{i-1}+1}^{J} \prod_{j \in \mathrm{K}} u_{j}$

where $\mathrm{K}=\left\{\mathrm{J}\left[w_{1}\right], \mathrm{J}\left[w_{2}\right], \ldots, \mathrm{J}\left[w_{i}\right]\right\}^{2}$, to expand the product in (28), one obtains

$$
\begin{aligned}
& \mathrm{M}_{2}=1+(-1)^{J} \Upsilon_{\mathrm{J}}+ \\
& \sum_{i=1}^{J-1}(-1)^{i} \sum_{w_{1}=1}^{J-i+1} \sum_{w_{2}=w_{1}+1}^{J-i+2} \cdots \sum_{w_{i}=w_{i-1}+1}^{J} \Upsilon_{\mathrm{K}} \\
& \text { where } \mathrm{C}=\{\mathrm{K} \mathrm{J}\} \text { and } \\
& \Upsilon_{\mathrm{C}}=\mathrm{E}_{\left|h_{L D 2}\right|^{2}}\left\{\prod_{j \in \mathrm{C}} \mathrm{Q}_{j} \mathrm{~T}_{j}\right\}
\end{aligned}
$$

To complete the derivation of the exact closed-form representation of $\mathrm{M}_{2}$, we firstly substitute (31) into (35):

$$
\begin{array}{r}
\Upsilon_{\mathrm{C}}=\mathrm{E}_{\left|h_{L D 2}\right|^{2}}\left\{\prod_{j \in \mathrm{C}} \mathrm{Q}_{j} e^{-\tau_{S}\left(\varphi_{j D 2}+\left.\left.\frac{\rho^{2} P_{L}}{\lambda_{j D 2} P_{j}}\right|_{L D 2}\right|^{2}\right)}\right\} \\
=\mathrm{E}_{\left|h_{L D 2}\right|^{2}}\left\{e^{-\left|h_{L D 2}\right|^{2} \tau_{S} P_{L} \sum_{j \in C} \frac{\rho^{2}}{\lambda_{j D 2} P_{j}}}\right\} \prod_{j \in \mathrm{C}} \mathrm{Q}_{j} e^{-\tau_{S} \varphi_{j D 2}} \\
\text { Since } h_{L D 2} \sim \mathrm{CN}\left(0, \lambda_{L D 2}\right), \text { the pdf of } \\
\left|h_{L D 2}\right|^{2} \quad \text { is } f_{\left|h_{L D 2}\right|^{2}}(x)=e^{-x / \lambda_{L D 2} / \lambda_{L D 2}, x \geq 0 .}
\end{array}
$$
Using this fact in (36), one then obtains

$$
\begin{aligned}
\Upsilon_{\mathrm{C}} & =\int_{0}^{\infty} e^{-x \tau_{S} P_{L} \sum_{j \in \mathrm{C}} \frac{\rho^{2}}{\lambda_{D 2} P_{j}}} f_{\left|h_{L D 2}\right|^{2}}(x) d x \prod_{j \in \mathrm{C}} \mathrm{Q}_{j} e^{-\tau_{S} \varphi_{j D 2}} \\
& =\int_{0}^{\infty} e^{-x \tau_{S} P_{L} \sum_{j \in \mathrm{C}} \frac{\rho^{2}}{\lambda_{j D 2} P_{j}}} \frac{e^{-x / \lambda_{L D 2}}}{\lambda_{L D 2}} d x \prod_{j \in \mathrm{C}} \mathrm{Q}_{j} e^{-\tau_{S} \varphi_{j D 2}} \\
& =\frac{\prod_{j \in \mathrm{C}} \mathrm{Q}_{j} e^{-\tau_{S} \varphi_{j D 2}}}{1+\tau_{S} \lambda_{L D 2} P_{L} \sum_{j \in \mathrm{C}} \frac{\rho^{2}}{\lambda_{j D 2} P_{j}}}
\end{aligned}
$$

Plugging (37) into (34) and then, inserting the result together with (27) into (25), one obtains the exact closed-form representation of $O P$.

\section{ILLUSTRATIVE RESULTS}

This section presents various results with arbitrary fading powers as $\left\{\lambda_{j D 2}\right\}_{j=1}^{5}=\{11.7757$,

11.6284,5.0188,11.9693,9.2398\},

$\lambda_{L D 1}=\lambda_{L D 2}=0.6905$,

$\left\{\lambda_{j L 2}\right\}_{j=1}^{5}=\{3.5696,1.6902$,

$2 \mathbf{J}[j]$ is the value of the $j^{\text {th }}$ element in the $\mathbf{J}$ set. 
$4.1890,5.3979,3.6321\}, \quad \lambda_{L L 1}=\lambda_{L L 2}=$ 14.2668,

$\left\{\lambda_{L j 1}\right\}_{j=1}^{5}=\{1.7106,0.9601,2.5613$,

2.1784, 1.8496\},

$\left\{\lambda_{S j 1}\right\}_{j=1}^{5}=\{5.5479,4.6852$,

11.8926, 4.6987, 6.7476\}, $\quad \lambda_{S L 1}=1.2761$,

$\lambda_{s D 1}=1 ; P_{k m}=P_{m}, \forall k \in\{S, \mathrm{~J}\} ; \eta_{L}=0.5$

bits $/ \mathrm{s} / \mathrm{Hz}$ and $\eta_{S}=0.2 \mathrm{bits} / \mathrm{s} / \mathrm{Hz}$. In the sequel, three different relay sets $\left(\left\{\mathrm{UR}_{1}\right\},\left\{\mathrm{UR}_{j}\right\}_{j=1}^{3}\right.$, $\left.\left\{\mathrm{UR}_{j}\right\}_{j=1}^{5}\right)$ are illustrated for $J=1,3,5$, correspondingly.

Figure 2 illustrates $O P$ with respect to the variation of $\rho$ for $P_{L} / N_{0}=16 \mathrm{~dB}, P_{m} / N_{0}=14 \mathrm{~dB}$, $\mu=0.05$. It is observed that the simulation and the analysis are in a perfect agreement. Also, the unlicensed network is complete in outage for a wide range of $\rho$ (e.g., $\rho<0.935$ in Figure 2). When the channel estimation is better (e.g., $\rho \geq$ 0.935 in Figure 2), the outage performance of the unlicensed network is dramatically enhanced. Moreover, the increase in the number of relays significantly improves the outage performance. This comes from the fact that the larger $J$, the higher chance to select the best relay, and hence, the smaller the outage probability.

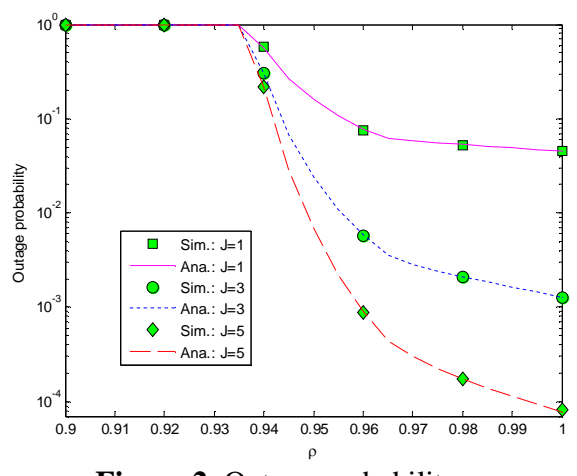

Figure 2. Outage probability versus $\rho$

Figure 3 demonstrates $O P$ with respect to the variation of $\mu$ for $P_{m} / N_{0}=14 \mathrm{~dB}, \rho=0.97, P_{L} / N_{0}$
$=16 \mathrm{~dB}$. It is observed that the analysis perfectly matches the simulation. Additionally, the system performance is significantly better with larger number of relays. Moreover, some interesting comments are observed as follows:

- The high QoS (e.g., $\mu \leq 0.025$ in Figure 3) requirement in the licensed network causes the unlicensed network to be complete in outage.

- When the licensed network requires the moderate QoS (e.g., $0.025<\mu \leq 0.08$ in Figure 3), the outage performance of the unlicensed network is drastically improved with the increase in $\mu$.

- When the licensed network is not stringent in the QoS (i.e., low QoS requirement), the unlicensed network suffers error floor for large values of $\mu$ (e.g., $\mu>0.08$ in Figure 3 ).

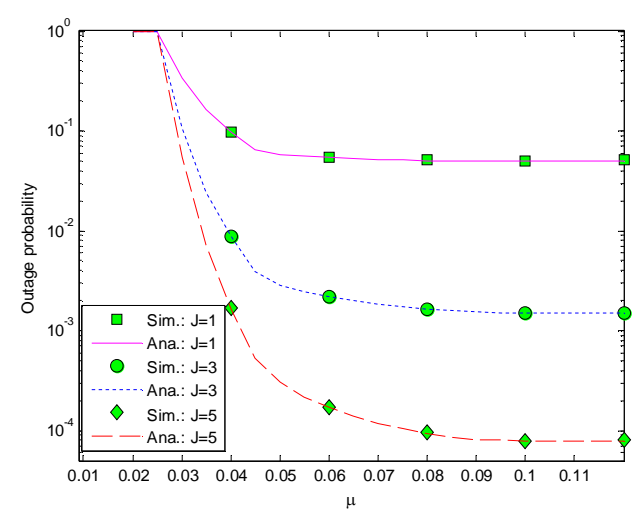

Figure 3. Outage probability versus $\mu$

The results in Figure 3 demonstrate that better performance of the licensed network (i.e., lower values of $\mu$ ) induces worse performance of the unlicensed network (i.e., larger values of $O P$ ) and vice versa. Therefore, the performance trade-off between the unlicensed network and the licensed network should be accounted when designing cooperative cognitive networks.

Figure 4 illustrates $O P$ with respect to the variation of $P_{L} / N_{0}$ for $P_{m} / N_{0}=14 \mathrm{~dB}, \rho=0.97$, and $\mu=0.05$. Results expose a perfect agreement 
between the analysis and the simulation. Additionally, the outage performance is significantly enhanced with larger number of relays as expected. Moreover, some interesting comments are observed as follows:

- For small values of $P_{L}$ (e.g., $P_{L} / N_{0} \leq 15 \mathrm{~dB}$ in Figure 4), the increase in $P_{L}$ substantially enhances the outage performance. This can be interpreted as follows. According to (17), $P_{L}$ is proportional to $\mathrm{L}$ while the power of unlicensed transmitters is controlled by the minimum of $\mathrm{L}$ and $P_{m}$, and hence, at small values of $P_{L}$ and the fixed value of $P_{m}$, the power of unlicensed transmitters is proportional to $P_{L}$, ultimately improving the performance of the unlicensed network as $P_{L}$ increases and the interference caused by the licensed network to the unlicensed network is not significant (due to small $P_{L}$ ).

- For large values of $P_{L}$ (e.g., $P_{L} / N_{0}>15 \mathrm{~dB}$ in Figure 4), the $\mathrm{L}$ term in (17) is larger than $P_{m}$ and hence, the transmit power of unlicensed users is fixed at the value of $P_{m}$ (e.g., $P_{m} / N_{0}=14 \mathrm{~dB}$ in Figure 4). Meanwhile, as $P_{L}$ is large and increases, the interference that the licensed network imposes on the unlicensed network dramatically increases, ultimately deteriorating the performance of the unlicensed network (i.e., increasing the outage probability). At the very large values of $P_{L}$ (e.g., $P_{L} / N_{0} \geq 37 \mathrm{~dB}$ in Figure 4 ), the unlicensed network is complete in outage.

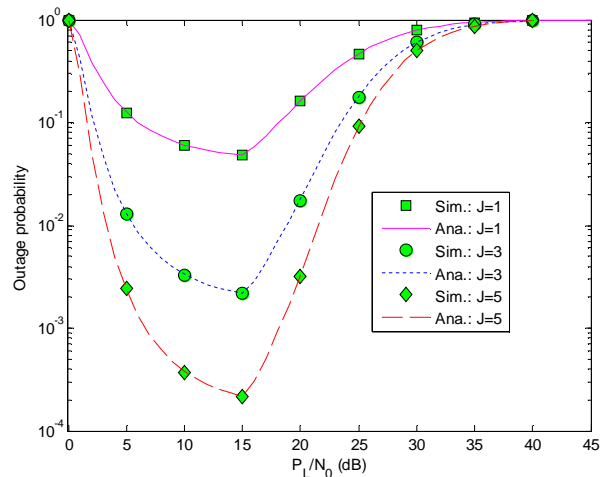

Figure 4. Outage probability versus $P_{L} / N_{0}$

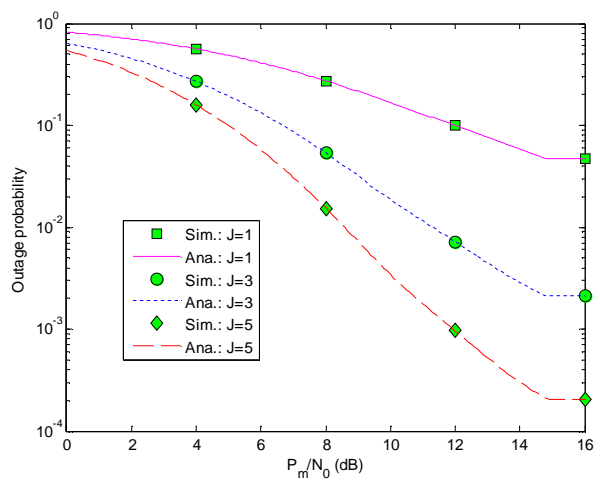

Figure 5. Outage probability versus $P_{m} / N_{0}$

Figure 5 demonstrates $O P$ with respect to the variation of $P_{m} / N_{0}$ for $P_{L} / N_{0}=16 \mathrm{~dB}, \mu=0.05$, and $\rho=0.97$. It is seen that the analysis and the simulation are in a perfect agreement. Also, the increase in $J$ dramatically enhances the system performance. Furthermore, the system performance is significantly improved with the increase in $P_{m}$. This can be interpreted as follows. Since $P_{m}$ upper bounds the power of unlicensed transmitters (e.g., (17)) and hence, the larger $P_{m}$, the larger the transmit power, ultimately remedying the corresponding outage probability. Nevertheless, the unlicensed network experiences performance saturation at large values of $P_{m} / N_{0}$ (e.g., $P_{m} / N_{0} \geq 15 \mathrm{~dB}$ in Figure 5). This comes from the fact that the power of unlicensed transmitters in (17) is controlled by the minimum of $P_{m}$ and $P_{L}$ and hence, as $P_{m}$ is larger than a certain level (e.g., $P_{m} / N_{0} \geq 15 \mathrm{~dB}$ in Figure 5), the power of unlicensed transmitters is completely determined 
by $P_{L}$, making the outage performance unchanged regardless of any increase in $P_{m}$. However, the error floor level is drastically reduced with respect to the increase in $J$.

\section{CONCLUSION}

This paper analyzes the outage performance of cooperative cognitive networks with the proactive relay selection and the selection combining under channel information error, licensed users' interference, i.n.i fading channels, licensed outage constraint and maximum transmit power constraint. To meet these power constraints and account for channel information error and licensed users' interference, we proposed an appropriate power allocation scheme for unlicensed users. Then, to analytically assess the system performance in key operation parameters without exhaustive simulations, we suggested an exact closed-form outage probability formula. Various results demonstrate that $i$ ) mutual interference between the licensed network and the unlicensed network establishes a performance trade-off between them; $i$ ) channel information error dramatically degrades system performance; iii) the unlicensed network suffers the error floor; $i v)$ the relay selection plays an important role in system performance improvement as well as system resource savings.

\section{ACKNOWLEDGEMENT}

This research is funded by Vietnam National Foundation for Science and Technology Development (NAFOSTED) under grant number 102.04-2014.42.

\section{Hiệu năng của mạng nhận thức hợp tác có chọn lựa relay chủ động và kết hợp chọn lọc}

\section{- Hồ Văn Khương}

- Võ Quế Sơn

- Lưu Thanh Trà

Trường Đại học Bách Khoa - ĐHQG-HCM, Việt Nam

- Phạm Hồng Liên

Đại học Sư phạm Kỹ Thuật, TP. Hồ Chí Minh, Việt Nam

\section{TÓM TẤT}

Bài báo này đề xuất một khung phân tích xác suất dừng cho mạng nhận thức hợp tác có chọn lựa relay chủ động và kết hợp chọn lọc dưới ràng buộc xác suất dừng sơ cấp, ràng buộc công suất phát tối đa, phân bố fading không đồng nhất, thông tin kênh 
truyền sai, và can nhiễu của người dùng so' cấp. Hướng đến mục tiêu này, trước hết chúng tôi đề xuất phân bổ công suất cho các máy phát thứ cấp để đảm bảo các ràng buộc công suất và tính đến thông tin kênh truyền sai và can nhiễu của người dùng sơ cấp. Sau đó, chúng tôi đề xuất một biểu thức xác suất dừng chính xác dạng kín cho mạng thứ cấp để đánh giá nhanh hiệu năng hệ thống và

Từ khóa: Chọn lựa relay chủ động, Thông tin kênh truyền sai, Cognitive radio.

\section{REFERENCES}

[1]. FCC, Spectrum policy task force report, ET Docket 02-135 (2002).

[2]. Goldsmith, S. A. Jafar, I. Maric, and S. Srinivasa, Breaking spectrum gridlock with cognitive radios: An information theoretic perspective, Proceedings of the IEEE, vol. 97, pp. 894-914 (2009).

[3]. J. N. Laneman, D. N. C. Tse, and G. W. Wornell, Cooperative diversity in wireless networks: Efficient protocols and outage behavior, IEEE Trans. Inf. Theory, vol. 50, pp. 3062-3080 (2004).

[4]. N. H. Giang, V. N. Q. Bao, and H. N. Le, Cognitive underlay communications with imperfect CSI: network design and performance analysis, in Proc. IEEE ATC, HoChiMinh City, Vietnam, pp. 18-22, 2013.

[5]. H. Ding, J. Ge, D. B. da Costa, and Z. Jiang, Asymptotic analysis of cooperative diversity systems with relay selection in a spectrumsharing scenario, IEEE Trans. Veh. Tech., vol. 60, pp. 457-472 (2011).

[6]. X. Zhang, J. Xing, Z. Yan, Y. Gao, and W. Wang, Outage performance study of cung cấp các hiểu biết hữu ích về giới hạn hiệu năng. Nhiều kết quả cho thấy sự tương nhượng hiệu năng giữa mạng sơ cấp và mạng thứ cấp, nền lỗi trong mạng thứ cấp, sự suy giảm hiệu năng hệ thống đáng kể do thông tin kênh truyền sai và can nhiễu của người dùng sơ cấp, và sự cải thiện hiệu năng đáng kể do sự gia tăng về số lượng relay. cognitive relay networks with imperfect channel knowledge, IEEE Commu. Lett., vol. 17, pp. 27-30 (2013).

[7]. T. L. Thanh, V. N. Q. Bao, and B. An, On the performance of outage probability in underlay cognitive radio with imperfect CSI, in Proc. IEEE ATC, HoChiMinh City, Vietnam, pp. 125-130 (2013).

[8]. Q. Wu, Z. Zhang, and J. Wang, Outage analysis of cognitive relay networks with relay selection under imperfect CSI environment, IEEE Commun. Lett., vol 17, pp. 1297-1300 (2013).

[9]. H. A. Suraweera, P. J. Smith, and M. Shafi, Capacity limits and performance analysis of cognitive radio with imperfect channel knowledge, IEEE Trans. Veh. Tech., vol. 59, pp. 1811-1822 (2010).

[10].K. Tourki, K. A. Qaraqe, and M. S. Alouini, Outage analysis for underlay cognitive networks using incremental regenerative relaying, IEEE Trans. Veh. Tech., vol. 62, pp. 721-734 (2013). 